\title{
Population genomics and analysis of agronomic traits of green gram (Vigna radiata) and black gram (Vigna mungo)
}

Sokolkova A.B. ${ }^{1 *}$, Vishnyakova M.A. ${ }^{2}$, Schafleitner R. ${ }^{3}$, von Wettberg E.B. ${ }^{1,4}$, Samsonova M.G. ${ }^{1}$, Nuzhdin S.V. ${ }^{1,5}$

${ }^{1}$ Peter the Great St. Petersburg Polytechnic University, St. Petersburg, Russia

${ }^{2}$ N.I. Vavilov All-Russian Institute of Plant Genetic Resources (VIR), St. Petersburg, Russia

${ }^{3}$ World Vegetable Center (WorldVeg), Tainan, Taiwan

${ }^{4}$ University of Vermont, Burlington, VT, USA

${ }^{5}$ University of Southern California, Los Angeles, CA, USA

*e-mail: alyonasok@yandex.ru

Vigna radiata and Vigna mungo are two important Asian pulse crops, important as dried seeds, sprouts, and in the green form as vegetables. Among the merits of these crops is the presence in seeds of at least $25 \%$ protein and essential aminoacids such as lysine, histidine and tryptophan, which are not produced by the human body, many vitamins and minerals. With good heat and drought tolerance, these crops are often grown as summer pulses in contrast to winter pulses such as chickpea and lentil, making them important for food security and nutritional diversity in many parts of Asia. The World Vegetable Gene Bank, in Taiwan, houses a unique genebank of green gram (Vigna radiata). Phenotyping of 293 accessions of the mini-core collection of green gram (Vigna radiata) from the World Vegetable Gene Bank (Taiwan) at Kuban experimental station of VIR in 2018 revealed a wide range of inter-varietal variability. Genotyping by sequencing of these accessions from different countries identified 8,466 segregating single nucleotide polymorphisms (SNP). We performed Genome-wide association study (GWAS) to find associations between SNPs and phenotypic data obtained at Kuban experimental station. GWAS analysis identified a large number of genome intervals and potential gene candidates that may affect important agronomic traits. 